\title{
ENRAIZAMENTO DE ESTACAS LENHOSAS DE PESSEGUEIRO CV. MARFIM EM DIFERENTES CONCENTRAÇÕES DE ÁCIDO INDOLBUTÍRICO
}

\author{
ROOTING OF WOODEN CUTTINGS OF PEACH CV. MARFIM BY \\ DIFFERENT IBA CONCENTRATION
}

\author{
Ubirajara Ribeiro MINDÊLLO NETO' \\ André Nunes Loula TORRES ${ }^{2}$ \\ Elcio HIRANO'
}

\begin{abstract}
RESUMO
O experimento foi conduzido em câmara de nebulização da Embrapa Transferência de Tecnologia, Canoinhas, SC, e teve como objetivo avaliar o efeito do ácido indolbutírico (AIB) no enraizamento de estacas lenhosas de pessegueiro cv. Marfim. Estacas lenhosas foram tratadas com ácido indolbutírico nas concentrações de $0,100,500,1.000$ e $5.000 \mathrm{mg}^{-L^{-1}}$ e plantadas em bandejas de poliestireno expandido com 72 células, contendo como substrato areia de granulometria média, e posteriormente colocadas para enraizar. Avaliaram-se a porcentagem de estacas enraizadas, porcentagem de estacas mortas e número de raízes. As três características analisadas mostraram um efeito quadrático em relação a aumentos nos níveis de AIB. A concentração de AIB que proporcionou maior enraizamento foi $2.966 \mathrm{mg}^{\mathrm{L}} \mathrm{L}^{-1}$, com $81,92 \%$ de estacas enraizadas. Das concentrações de AIB que resultaram na menor porcentagem de estacas mortas e maior número de raízes foram 3.075 e $2.941 \mathrm{mg} \cdot \mathrm{L}^{-1}$, respectivamente.
\end{abstract}

Palavras-chave: estaquia, AIB, Prunus persica (L.) Batsch.

\begin{abstract}
This work was carried out in mistchamber at EMBRAPA Technology Transference at Canoinhas-SC with aim to evaluate the effect of indolbutyric acid (IBA) on rooting of wooden cuttings of peach cv. Marfim. Wooden cuttings were treated with IBA at different concentrations $\left(0,100,500,1.000\right.$ and $\left.5.000 \mathrm{mg}^{-\mathrm{L}^{-1}}\right)$ and planted in expanded polyestirene trays with 72 cells, with medium granulometric sand as substrate. It were evaluated percentage of rooted cuttings, percentage of dead cuttings and the number of roots per cuttings. The three analised characteristics showed a quadratic effect with crescent concentrations of IBA. The concentration of IBA wich presented highest rooting was $2.966 \mathrm{mg} . \mathrm{L}^{-1}$ with $81,92 \%$ of rooted cuttings. The concentration of IBA wich presented lowest dead root and highest number of roots were 3.075 and $2.941 \mathrm{mg}^{-L^{-1}}$ respectively.
\end{abstract}

Key-words: cuttings, IBA, Prunus persica (L.) Batsch.

\footnotetext{
${ }^{1}$ Engenheiro Agrônomo, M.Sc., Pesquisador, Embrapa Transferência de Tecnologia/SNT Canoinhas, Rod. BR 280, km 219, Bairro Água Verde, Caixa Postal 317, CEP 89.460-000, Canoinhas, SC. E-mail: ubirajara.encan@embrapa.br. autor correspondente.

${ }^{2}$ Engenheiro Agrônomo, Dr., Pesquisador, Epagri/Estação Experimental de Canoinhas, SC.
} 


\section{INTRODUÇÃO}

O pessegueiro (Prunus persica (L.) Batsch) é uma das espécies frutíferas de clima temperado mais plantadas no Brasil, com área cultivada de aproximadamente 22.000 ha (1), estando na região Sul do Brasil os maiores pomares desta Rosaceae.

A expansão da persicultura é atrelada a introdução de novas cultivares e de técnicas que aumentem a oferta de mudas para produtores. Atualmente, a propagação do pessegueiro baseia-se na enxertia de borbulhas em porta-enxertos provenientes de sementes $(15,16)$. Entretanto, este método pode não ser vantajoso, pois pode ocorrer segregação genética dos porta-enxertos (6), gerando indivíduos que variam morfologicamente e fisiologicamente entre si (13), podendo perder certas características agronômicas desejáveis da cultivar utilizada como porta-enxerto.

Dentre as principais vantagens da propagação vegetativa, em plantas de pessegueiro, por meio da técnica da estaquia está a obtenção de um número elevado de mudas, rapidez, baixo custo e manutenção das características desejáveis da espécie $(4,11)$. Contudo, este método de propagação pode não ser viável, devido a baixa capacidade de enraizamento de certas cultivares de pessegueiro (17), especialmente as mais recentes, como por exemplo a recém lançada $c v$. Marfim.

$\mathrm{Na}$ propagação por meio da estaquia, é necessária a aplicação exógena de reguladores de crescimento, como o ácido indolbutírico, promovendo maior enraizamento. A auxina, quando é aplicada em segmento de caule, é transportada basípetamente, por um mecanismo polar, através do floema da planta, causando um rápido acúmulo da substância na porção basal. A auxina acumulada neste local causará a produção de uma dilatação ou calo $(14,18)$. Este calo é um tecido cicatricial, composto por células parenquimáticas, resultantes de novos centros meristemáticos que induzem a formação de raízes $(6,7)$. Contudo, altas concentrações de auxinas, necessárias nos estágios iniciais de indução do enraizamento, são inibitórias à organização e crescimento dos primórdios radiculares (8). O aumento na concentração da auxina inicialmente estimula a emissão de raízes, até um ponto máximo, acima do qual torna-se inibitória (2).

Vários trabalhos tem demonstrado que o uso de AIB é eficiente na emissão de raízes, entretanto, a concentração ótima do regulador de crescimento em cada cultivar ainda não está bem definida. Em estudo com estacas lenhosas, em três cultivares de pessegueiro, tratadas com AIB a $3.000 \mathrm{mg} \cdot \mathrm{L}^{-1}$, Barradas (3), obteve até $70 \%$ de enraizamento. Fachinello et al. (6) avaliaram estacas lenhosas de ramos dobrados de pessegueiro das cultivares Capdeboscq, Convênio e Diamante, e observaram que as melhores concentrações para ampliar a porcentagem de estacas enraizadas situam-se entre 2.000 e 3.000 mg. L $^{-1}$ de AIB. A concentração de AIB que promove um melhor enraizamento em estacas lenhosas de pessegueiro, segundo reporta Couvillon (5), situa-se na faixa de 1.000 a $5.000 \mathrm{mg} \cdot \mathrm{L}^{-1}$. Já, Kaundal et al. (9), estudando o comportamento de quatro cultivares no enraizamento de estacas lenhosas, obtiveram valores entre 38,6 a $51,8 \%$, em concentração de $500 \mathrm{mg} \cdot \mathrm{L}^{-1}$ de AIB.

Este trabalho objetivou avaliar a capacidade de enraizamento de estacas lenhosas da cultivar Marfim, quando submetida a diferentes concentrações de ácido indolbutírico.

\section{METODOLOGIA}

O experimento foi instalado em câmara de nebulização intermitente, localizada nas dependências da Embrapa Transferência de Tecnologia, situada no município de Canoinhas, SC.

Estacas lenhosas foram coletadas após a poda de inverno, em plantas com dois anos de idade, em julho de 2003. Em seguida, levadas para laboratório para padronização em comprimento de $20 \mathrm{~cm}$ e diâmetros variando entre 8 a $10 \mathrm{~mm}$.

Todas as estacas foram tratadas com ácido indolbutírico (AIB) por imersão rápida por 5 segundos, nas concentrações de $0,100,500,1.000$ e $5.000 \mathrm{mg}^{-\mathrm{L}^{-1}}$. Na concentração de $0 \mathrm{mg} \cdot \mathrm{L}^{-1}$ foi utilizado água destilada como testemunha. Posteriormente, foram colocadas para enraizar em bandejas de poliestireno expandido com 72 células, contendo como substrato areia de granulometria média. Em seguida foram colocadas em câmara de nebulização intermitente acionada por temporizador. O turno de rega estabelecido foi de 4 segundos a cada 15 minutos. Após 64 dias do início do experimento foi realizada a coleta dos dados.

$O$ delineamento experimental utilizado foi 0 inteiramente casualizado com quatro repetições, com dez estacas por repetição. Foram avaliadas as seguintes variáveis: porcentagem de estacas enraizadas, porcentagem de estacas mortas e número de raízes. Efetuou-se a transformação dos dados na variável número de raízes para raiz quadrada de $x+1$. Os resultados foram submetidos à análise de variância e regressão polinomial. O nível de probabilidade do erro utilizado foi de $5 \%$. Os pontos de máxima e mínima das curvas foram estimados por meio da sua derivada primeira.

\section{RESULTADOS E DISCUSSÃO}

A porcentagem de estacas enraizadas ajustouse a um modelo quadrático em relação a aumentos na concentração de AIB (Figura 1). A porcentagem de estacas enraizadas aumentou até a concentração de $2.966 \mathrm{mg} \cdot \mathrm{L}^{-1}$ de AIB, com enraizamento máximo de $81,92 \%$. Estes resultados estão de acordo com a literatura $(3,6)$ que citam que concentração ideal do AIB está entre 2.000 e $3.000 \mathrm{mg} \cdot \mathrm{L}^{-1}$. Isto sugere que 
a concentração ótima para enraizamento nas cultivares já estudadas foi semelhante à obtida para a cultivar Marfim, embora tenha sido observado um potencial de enraizamento diferente para cada uma delas.

Verifica-se, ainda, pela Figura 1, que as concentrações mais baixas de AIB, entre 0 a $1.000 \mathrm{mg}^{-\mathrm{L}^{-1}}$, apesar de promoverem na porcentagem de enraizamento a medida em que há aumento na dose utilizada, não foram tão eficientes quanto a utilização de concentrações mais altas, entre 1.500 e $4.500 \mathrm{mg}^{-\mathrm{L}^{-1}}$ de AIB. Isto demonstra que as estacas lenhosas de pessegueiro necessitam de concentrações superiores a 1.000 mg.L-1 de AIB (5) para enraizamento.

Observou-se redução na porcentagem de estacas enraizadas quando utilizadas doses superiores a $2.966 \mathrm{mg} \cdot \mathrm{L}^{-1}$ de AIB (Figura 1). Estes dados estão de acordo com Jarvis (8), que cita que altas concentrações de auxinas podem provocar inibição no enraizamento e também evidencia uma concordância com os dados obtidos por Alvarenga e Carvalho (2).

O método de propagação vegetativa por meio da estacas lenhosas requer o uso de altas concentrações de auxinas, segundo reportam Hartmann et al. (7) variando de 5.000 a 10.000 mg.L-1. De um certo modo, não podemos afirmar que para todas as espécies a faixa ideal da concentração do regulador de crescimento esteja entre estes limites, pois outros fatores estão relacionados com a promoção do enraizamento, principalmente o genótipo de cada uma delas. Na cultura do pessegueiro, a literatura mostra que a maioria das cultivares propagadas por estacas lenhosas requerem uma concentração de AIB até $5.000 \mathrm{mg} \cdot \mathrm{L}^{-1}(3,5,6,9)$. Contudo, concentrações de $5.000 \mathrm{mg}^{-1} \mathrm{~L}^{-1}$ de AIB podem inibir o enraizamento da cultivar Marfim, conforme verificado no presente trabalho.

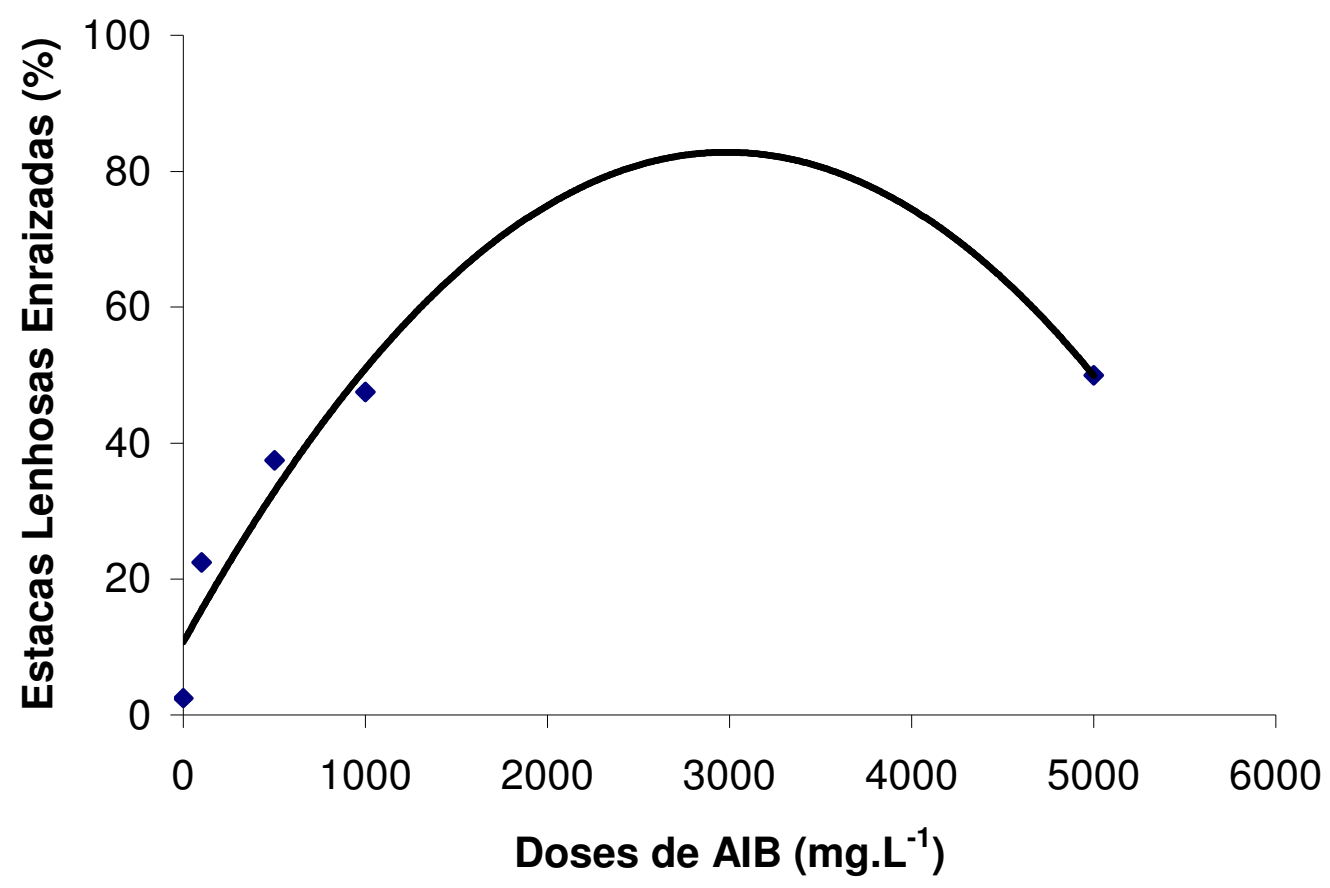

FIGURA 1 - Porcentagem de enraizamento estacas lenhosas de pessegueiro $\mathrm{cv}$. Marfim, tratadas com diferentes doses de AIB $\left(\mathrm{mg} \cdot \mathrm{L}^{-1}\right)$.

A porcentagem de estacas mortas ajustou-se a um modelo quadrático em relação a aumentos na concentração de AIB (Figura 2). A variável porcentagem de estacas mortas teve na concentração de $3.075 \mathrm{mg} . \mathrm{L}^{-1}$ de AIB, a menor mortalidade $(21,1 \%)$. Estes resultados são semelhantes aos obtidos por Mayer e Pereira (10), que em trabalho com enraizamento de clones de umezeiro, verificaram que a porcentagem de estacas mortas situou-se entre $18,75 \%$ a $35,0 \%$.
Um cuidado importante durante o processo de enraizamento de estacas é não estender demais o tempo em que as mesmas ficam na câmara de nebulização, pois, relata Nachtigal (12) que o baixo enraizamento deve-se ao excesso de umidade do ambiente e do substrato, fazendo com que aumente a mortalidade das estacas. Entretanto, no presente trabalho, a permanência de 64 dias na câmara de nebulização foi considerada suficiente para manter um bom enraizamento de estacas lenhosas na cultivar Marfim. 


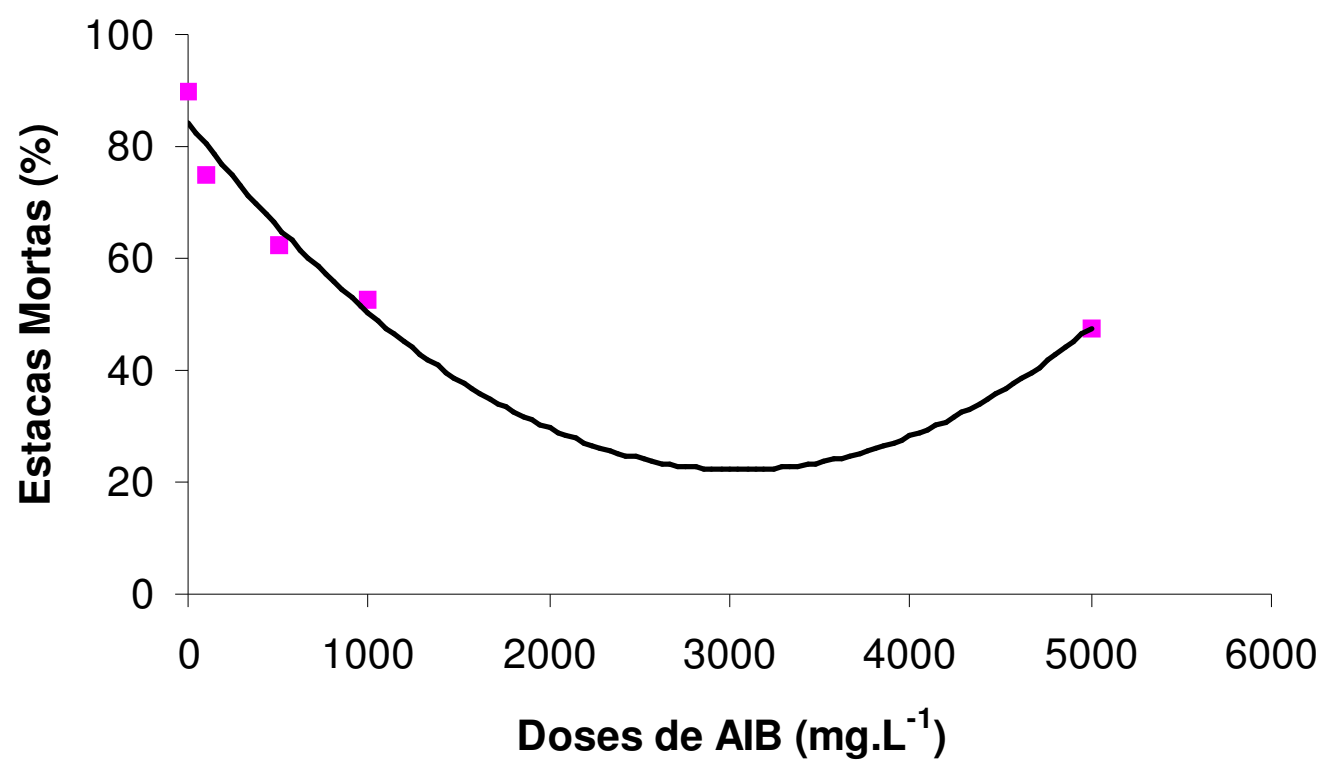

FIGURA 2 - Porcentagem de estacas mortas de pessegueiro cv. Marfim, tratadas com diferentes doses de AIB $\left(\mathrm{mg}^{\mathrm{L}} \mathrm{L}^{-1}\right)$.

O número médio de raízes ajustou-se a um modelo quadrático em relação a aumentos na concentração de AIB (Figura 3). Observa-se que o número médio de raízes aumentou entre 0 a 2.941 mg. L ${ }^{-1}$ e acima dessa concentração, os resultados decrescem. Verifica-se ainda, pela mesma figura, que na concentração ótima de AIB (2.941 mg. L-1 $)$, o número médio de raízes foi de 4,37. Este resultado é semelhante ao encontrado por Rufato e Kersten (15) na cultivar BR2, os quais relataram que o número médio de raízes foi de 4,76, em concentração de $4.000 \mathrm{mg} . \mathrm{L}^{-1}$ de AIB, entretanto, para a cultivar Esmeralda, em concentração de $3.000 \mathrm{mg} \cdot \mathrm{L}^{-1}$ de AIB, o número de raízes aumentou para 11,25. Isto demonstra que para cada cultivar há uma concentração adequada do regulador de crescimento. Nem todas enraízam na mesma proporção, e também não emitem raízes na mesma quantidade, sugerindo que estas características também são influenciadas pela genética da planta.

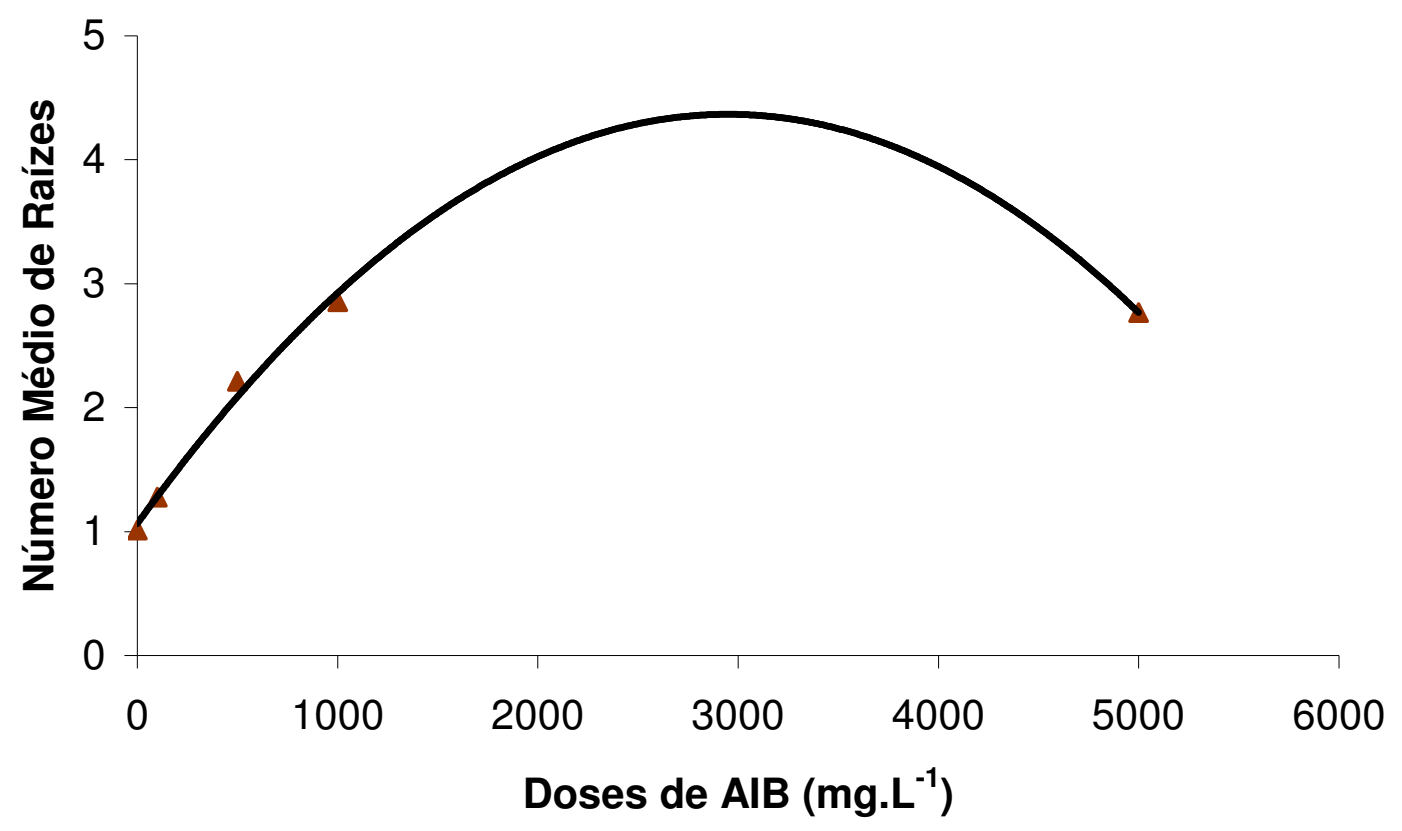

FIGURA3 - Número de raízes (dados transformados, $\operatorname{de} \operatorname{AIB}\left(\mathrm{mg} \cdot \mathrm{L}^{-1}\right)$. 


\section{CONCLUSÃO}

1 - A concentração de AIB que resultou na maior porcentagem de estacas enraizadas foi de $2.966 \mathrm{mg} \cdot \mathrm{L}^{-1}$ $(81,92 \%)$.

2 - A aplicação de AIB até a dose de $2.941 \mathrm{mg} \cdot \mathrm{L}^{-1}$ amplia o número de raízes $(4,37)$ formadas, mas acima disto o efeito é inibitório.

3 - O tempo de 64 dias de permanência das estacas na câmara de nebulização intermitente foi suficiente para manter um bom enraizamento das estacas da $c v$. Marfim, sem aumentar a mortalidade das mesmas.

\section{REFERÊNCIAS BIBLIOGRAFICAS}

1. AGRIANUAL 2001: Anuário de agricultura brasileira. São Paulo: FNP Consultoria e Comércio, 2001. p. $452-457$.

2. ALVARENGA, L. R.; CARVALHO, V. D. Uso de substâncias promotoras de enraizamento de estacas de frutíferas. Informe Agropecuário. Belo Horizonte, v. 9, n. 101, p. 47-55, 1983.

3. BARRADAS, C. I. N. Efeito de quatro concentrações do ácido-3-indolbutírico, sobre o enraizamento de estacas lenhosas e formação de mudas de três cultivares de pessegueiro (Prunus persica (L.) Batsch) em duas épocas. Pelotas: Universidade Federal de Pelotas, 1980. 93f. Dissertação (mestrado)- Fruticultura de Clima Temperado - FAEM/Pelotas.

4. CHALFUN, N. N. J.; HOFFMANN, A. Propagação do pessegueiro e da ameixeira. Informe Agropecuário, Belo Horizonte, v. 18, n. 189, p. 23-29, 1997.

5. COUVILLON, G. A. Rooting responses to different treatments. Acta Horticulturae (Wageningen), n. 227, p. 187-196, 1988.

6. FACHINELLO, J. C.; HOFFMANN, A.; NACHTIGAL, J. C. et al. Propagação de plantas frutíferas de clima temperado. 2 ed. Pelotas:Ufpel, 1995. 178p.

7. HARTMANN, H. T.; KESTER, D. E; DAVIES JUNIOR, F. T.; GENEVE, R. L. Plant propagation: principles and practices. Upper Saddle Rwir: Prentice Hall, 1997.770p.

8. JARVIS, B. C. Endogenous control of adventitious rooting in nonwoody cuttings. In: JACKSON, M. B. New root formation in plants and cuttings, Lancaster: Dordrecht, p. 194-222, 1986.

9. KAUNDAL, G. S.; KANWAR, J. S.; BRAR, S. S.; DEOL, I. S.; CHANANA, Y. R. Effect of growth regulators on the rhizogenesis of peach cultivars. Indian Journal of Horticulture, Bangalore, v. 50, n. 4, p. 318-326, 1993.

10. MAYER, N. A.; PEREIRA, F. M. Enraizamento de estacas herbáceas de quatro clones de umezeiro (Prunus mume Sieb. et Zucc.) durante o inverno ameno, em Jaboticabal-SP. Revista Brasileira de Fruticultura, Jaboticabal, v. 25, n. 3, p. 505-507, 2003.

11. MÉSEN, F.; NEWTON, A. C.; LEAKEY, R. R. B. Vegetative propagation of Cordia alliodora (Ruiz \& Pavon) Oken: the effects of IBA concentration, propagation medium and cutting origin. Forest Ecology and Management, Amsterdam, v. 92, n. 1/3, p. 4554, 1997.

12. NACHTIGAL, J. C. Obtenção de porta-enxertos 'Okinawa' e de mudas de pessegueiro (prunus persica (L.) Batsch) utilizando métodos de propagação vegetativa. 1999. 165f. Tese (Doutorado em Agronomia) - Faculdade de Ciências Agrárias e Veterinárias, Universidade Estadual Paulista, Jaboticabal, 1999.

13. PASINATO, V.; NACHTIGAL, J. C.; KERSTEN, E. Enraizamento de estacas lenhosas de cultivares de ameixeira (Prunus spp.), em condições de campo. Scientia Agricola, Piracicaba, v. 55, n. 2, p. 265-268, 1998.

14. ROCHA, A. C. da; TAVARES, E. D.; SANDRINI, M.; CARVALHO, S. A.; SILVA, L. F. C. da. Propagação de três espécies de citros através do enraizamento de estacas verdes. Revista Brasileira de Fruticultura, Cruz das Almas, v. 10, n. 2, p. 31-33, 1988.

15. RUFATO, L.; KERSTEN, E. Enraizamento de estacas de pessegueiro (Prunus persica (L.) Batsch), cvs Esmeralda e BR2, submetidas à estratificação e ao ácido indol-butírico. Revista Brasileira de Fruticultura, Jaboticabal, v. 22, n. 2, p. 191-194, 2000.

16. TOFANELLI, M. B. D.; CHALFUN, N. N. J.; HOFFMANN, A. et al. Capacidade de enraizamento de estacas lenhosas e semilenhosas de cultivares de pessegueiro. Revista Ciência e Agrotecnologia, Lavras, v. 25, n. 4, p. 840-847, 2001.

17. TOFANELLI, M. B. D.; CHALFUN, N. N. J.; HOFFMANN, A. et al. Efeito do ácido indolbutírico no enraizamento de estacas de ramos semilenhosos de pessegueiro. Pesquisa Agropecuária Brasileira, Brasília, v. 27, n. 7, p. 939-944, 2002.

18. WAREING, P. F.; PHILLIPS, I. D. J. The control of growth \& diferentiation in plants. 2.ed. Oxford: Pergamon, 1978. 303p. 